\title{
Does Zika Really Have the Capacity to Affect the Nervous System and Cause Microcephaly or Intracranial Calcifications?
}

\author{
Lawrence Broxmeyer*, Refik Kanjhan \\ School of Biomedical Sciences Brisbane, University of Queensland, Brisbane, Australia \\ Email: *nyinstituteofmedresearch@verizon.net
}

Received 1 March 2016; accepted 9 May 2016; published 12 May 2016

Copyright (C) 2016 by authors and Scientific Research Publishing Inc.

This work is licensed under the Creative Commons Attribution International License (CC BY). http://creativecommons.org/licenses/by/4.0/

(c) (i) Open Access

\begin{abstract}
Although the Centers for Disease Control and Prevention (CDC) reports that brain abnormalities in infants with laboratory-confirmed Zika infection include microcephaly, disrupted brain growth, intracranial calcifications, and abnormal eye findings-it is not known presently if the Zika virus itself causes any of these. In a recent 2016 review of Zika dealing with possible brain abnormalities appearing with Zika, Melo et al. mention that among the Flaviviruses, which Zika is, such brain insults and pathologic findings are practically unheard of. Melo et al. conclude that until more cases are diagnosed and more histopathological proofs are obtained, the possibility of other causes besides Zika cannot be ruled out. This paper considers just such other possible causes that have, to this point, escaped general notice. The Aedes aegypti and other Aedes species can transmit tiny viral-like, cell-wall-deficient mycobacterial forms, independent of viruses, yet prevalent in the very same Rhesus Monkey used in the original 1952 Zika communication-which spoke of "A filterable transmissible agent". In addition, the universal fetal prenatal vaccination of Brazilian neonates is considered, strongly discouraged by The Royal Children's Hospital in Melbourne, which forbids BCG vaccination of pregnant women and those immunosuppressed or already having tuberculosis (TB) or AIDS. And finally thought is focused on the prime candidate itself, towards explaining what an alternative cause for "Zika" might look like-an infectious agent with transmissible, filterable, viral-like forms. One which can be transmitted by the very same Aedes mosquitoes that carry Zika-one that is neurotrophic, and extremely prevalent in Brazil-and that can disrupt brain growth, cause microcephalus, cause a fever, is sexually transmissible, instigates Guillain-Barré syndrome and causes cranial calcifications-the Mycobacterium tuberculosis complex, which includes the Mycobacterium africanum prevalent, yet completely ignored, in the Rhesus monkeys used in the original Zika study.
\end{abstract}

"Corresponding author.

How to cite this paper: Broxmeyer, L. and Kanjhan, R. (2016) Does Zika Really Have the Capacity to Affect the Nervous System and Cause Microcephaly or Intracranial Calcifications? Modern Research in Inflammation, 5, 20-30.

http://dx.doi.org/10.4236/mri.2016.52003 


\section{Keywords}

The Zika Virus, Microcephaly, Aedes aegypti, Flaws in Zika Diagnosis, Mycobacterium Tuberculosis

\section{Introduction}

Zika virus belongs to Flavivirus genus that is enveloped, with icosahedral and spherical geometries. The diameter is around $50 \mathrm{~nm}(40-65 \mathrm{~nm})$. Genomes are made of positive-sense single-stranded RNA (ssRNA) linear and non-segmented, around 10 - 11 kilobases in length. Flaviviruses are transmitted by the bite from an infected arthropod (mosquito or tick) and hence, classified as arboviruses. The yellow fever, dengue, and Zika viruses, which require mosquito vectors, but are well enough adapted to humans as to not necessarily, depend upon animal hosts. This property raises the possibility for Zika to be sexually transmittable. However, generally flaviviruses are considered as noncontagious, or not easily transmitted from human to human.

Zika virus is primarily transmitted via Aedes mosquitoes that are active during daytime, such as A. aegypti and A. albopictus. Entry into the host cell is achieved by attachment of the viral envelope protein $\mathrm{E}$ to host receptors, which mediates clathrin-mediated endocytosis. Replication follows the positive stranded RNA virus replication model. Positive stranded RNA virus transcription is the method of transcription. There are African and Asian lineages of the Zika virus, and the virus spreading in the Americas is most likely related to the Asian strain.

Zika fever was described back in early 1960s, as a relatively mild disease with only one in five persons developing symptoms, with no fatalities, but its true potential as a viral agent of disease is unknown. Common symptoms of Zika viral infection include mild headaches, maculopapular rash, fever, malaise, conjunctivitis (red eyes), and joint pains. Usually, Zika begins with a mild headache, and progresses to a maculopapular rash, fever, and back pain. Within couple of days, the rash fades, and within three days, the fever resolves and only the rash remains. Currently there is no available cure, vaccine or preventative drug. Treatment of patients is symptomatic, including rest, fluids, and paracetamol (acetaminophen). It is predicted that it may take two years to develop a vaccine, but 10 to 12 years before an effective Zika vaccine is approved by the regulators for public use.

The World Health Organization (WHO) declared an international emergency over the explosive spread of the mosquito-borne Zika virus, which is at present only weakly linked to birth defects in the Americas, saying it is an "extraordinary event". But by the same token, WHO officials say that it could be six to nine months before science proves or disproves any connection between Zika and the spike in the number of babies born in Brazil with abnormally small heads (microcephaly) and impaired brains. Since the Brazilian Zika outbreak began last spring, an estimated 500,000 to 1.5 million people have been infected and nearly 4000 infants have since been born with microcephalic small heads-which are about twenty times more than the prior year. And most of these occurred in Brazil's northeast. In the worst affected region of Brazil, approximately 1 percent of newborns are suspected of being microcephalic.

As international researchers rushed in to help, one thing and one thing only became obvious-that they were not sure exactly what was causing the phenomenon or how to address it.

\section{Paper-Thin Evidence That Connects Zika Virus to Microcephaly}

Out of the almost 4000 cases of Brazilian microcephaly, only six have been strongly linked to Zika virus via laboratory testing that confirms genetic material from the virus is present in the infant, Claudio Maierovitch, director of the Department of Communicable Disease Surveillance in Brazil's Ministry of Health told the WHO last week in Geneva [1]. Moreover, over decades, Zika disease has never before been known to cause microcephaly. Nor is there any direct evidence that it is causing it now. Microcephaly is traditionally thought to be caused by disease, exposure to toxic substances, or vague 'genetic' abnormalities. Also, although the Centers for Disease Control and Prevention (CDC) reports brain abnormalities in infants with laboratory-confirmed Zika infection include microcephaly, disrupted brain growth, intracranial calcifications, and abnormal eye findingsit is not known if the Zika virus itself causes any of these abnormalities [2]. Reportedly, there is already evidence the virus can cross the placental barrier. Zika has been detected in the amniotic fluid of two pregnant women with microcephalic fetuses in the Brazilian state of Paraiba. The greatest risk of transfer seems to be 
during the first trimester of pregnancy.

Also, disturbingly, Zika has also been linked with the future development of Guillain-Barré syndrome, an autoimmune disease that could lead to paralysis. But Zika traditionally lasts only a few days. Its symptoms, including a rash, joint pains, inflammation of the eyes and fever, tend to be way less debilitating than those of dengue fever. In fact, up to $80 \%$ of people (adults) infected with Zika may be asymptomatic.

\section{Flawed Diagnostics in Identification of Zika}

Even the methods used in detection of Zika leave much to be questioned. Finding Zika antibodies in newborns is no small task, as its antibody strongly resembles yellow fever and Dengue, both also common in Brazil. In addition when examining maternal blood, you would not only have to differentiate Zika from Yellow Fever and Dengue-but whether such antibody proof was new or a condition of the past. So what is being relied upon to detect recent infection are titers for immunoglobulin $\mathrm{M}$ antibodies (IgM) in umbilical cord blood. But exactly which infection remains a problem, although fetal dengue fever is rare.

And that is just the beginning of the holes in the diagnostic apparatus for the Zika. First, in order to establish a causative viral disease, actual diseased tissue under electron microscopy needs to confirm a significant amount of virus in not just one, but in many cases. This has heretofore hardly been the case. Second, the tests which are used to determine Zika, rely on antibodies and PCR's-both plagued by their own inaccuracies. Not only are false positive results common, but an increase in antibodies per se does not necessarily mean that the patient is sick or will get sick. At one point in the history of medicine, a positive antibody test was considered a good thing - the body's immune system was fighting back. It was only in the late $20^{\text {th }}$ century that the interpretation switched to the assertion that a positive antibody test meant that any person with a sufficient antibody titer was sick or soon going to be sick. This meant that more people than ever would be falsely diagnosed as being sick. Papers such as that of Peter Palese, of the Mount Sinai School of Medicine in Manhattan, are illustrative. Even in 1992, millions in China already had antibodies to the H5N1 influenza virus, meaning that they had contracted it and that their immune system had little trouble fending it off. An epidemic never resulted [3]. It also meant that should certain health agencies desire, they could blow up the number of "sick" individuals with disease to whatever level they desired.

Furthermore, and most obviously, if one labels a filterable, transmissible agent as a "virus" which in fact is a bacteria or mycobacteria, then a positive antibody test will automatically and falsely confirm that it was a "virus" after all that made the test positive.

\subsection{Does Zika Causes Microcephaly?}

The evidence for Zika being the culprit behind the microcephaly epidemic is anecdotal, such as in the case in which genetic material from Zika was detected in the blood of a microcephalic baby that died within 5 minutes of birth in the northern Brazilian state of Pará-or a subset of Brazilian woman who were reported to have positive serology and a rash before delivering their microcephalic babies. There is no definitive evidence. An earlier outbreak of Zika in French Polynesia also suggested that there was an increase in neurological impairment, according to the CDC. But again, the evidence was not bullet-proof.

\subsection{A Virus with a Sketchy History}

Then again, scientists know very little about Zika virus altogether. In fact, until 2007 there were only sporadic cases of people being infected with the virus (at least ones that were laboratory confirmed), with only small outbreaks in Africa and Southeast Asia occurring since the virus was discovered in Uganda in 1947.

In their landmark paper [4], virus-hunters G.W.A. Dick, S.F. Kitchen and A.J. Haddow, the discoverers of Zika, begin their study by stating that "The isolation of filterable viruses from mosquitoes taken in Uganda has already been recorded on several occasions"-and go on to name eight of them, published and unpublished. Included were the Mengo encephalomyelitis virus, the Bunyamwera virus, the Semliki Forest virus, and the Uganda S virus-most of which they themselves had spotted. Also they mentioned that "the purpose of this communication is to describe the isolation of yet another virus which is believed to be hitherto unrecorded". Enter the Zika virus. At one point, Dick Kitchen and Haddow would even forgo the word "virus"- simply describing Zika as "a filterable transmissible agent". 
By 1947, these scientists, originally researching yellow fever, placed a rhesus macaque in a cage in the Zika Forest (Zika meaning "overgrown” in the Luganda language), near the East African Virus Research Institute in Entebbe, Uganda. The monkey developed a fever, and researchers isolated from its serum "a transmissible agent" that would subsequently be first described as Zika virus in 1952. The instigator of the monkey's fever was from the bite or bites of the Aedes africanus mosquito. And proof that Zika was a virus relied only on that the Zika could pass through a small filter and subsequent "neutralization test techniques" of known Zika infested serum to test for it. These investigators only tested for known viruses transmitted by the Aedes africanus mosquito, although subsequently Aedes mosquitoes have been since shown to be capable of transmitting other infectious agents as well.

\subsection{Overlooked}

But Zika was far from the only thing threatening public health in Northeastern Brazil. And while it was Zika that was being portrayed as "the most alarming health crisis to hit Brazil in decades", this was hardly true. The real killer in Brazil was not Zika at all, but tuberculosis (TB) — showing its highest incidence in the very North and Northeastern regions of Brazil ostensibly now being bombarded with Zika [5]. If Brazil is currently ranked $16^{\text {th }}$ in a worldwide list of countries highly burdened with TB-then it is also TB that is Brazil's fourth cause of death for infectious diseases and its first cause of death among people living with HIV/aids-the same HIV that in conjunction with its omnipresent human and fowl TB can be responsible for microcephaly [6].

Zika was important and Zika could have tragic consequences-but the real killer was tuberculosis. And whereas Zika might have just been declared by WHO as a global health emergency-it was TB that after 2015 still remains the global emergency that WHO first proclaimed it to be in 1993, when it said that more than 30 million lives would be lost to tuberculosis in the next ten years after 1993 unless sufficient action was taken. Zika might have deformed, TB killed.

\section{The Mosquito}

The potential societal risk of Zika virus can be delimited by the distribution of the mosquito species that transmit it. The global distribution of the most cited carrier of Zika virus, A. aegypti, is expanding due to global trade and travel. Nor was the Zika and other viruses the only thing that an Aedes aegypti mosquito was capable of transmitting. Strange then, that it still went widely unnoticed, yet surely established, that mosquitoes such as Aedes aegypti and the species Culex can also transmit tubercular-like mycobacterial disease [7]-[11].

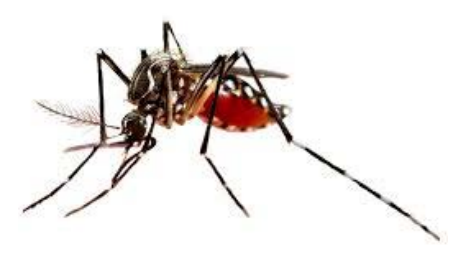

Bloodsucking insects such as mosquitoes can be significant vectors for many infectious diseases- and mycobacteria such as Mycobacterium tuberculosis are no exception. Golyshevskaya described how during blood suction after the sting of an Aedes aegypti mosquito he saw classic rod-shaped mycobacterial bacilli change into small, ultrafine viral-like coccoid forms-spherical in shape [12]. Such tubercular/mycobacterial forms have a dense cellular membrane often mistaken for the capsid of a virus. Although they can revert back to the classical tubercular bacilli at any time, their main usefulness inside the propagating mosquito was both the resilience of such tiny cell-wall-deficient coccoid forms while in the mosquito and as a side benefit to also make mycobacterial transmission easier through the mosquito while bloodsucking (Figure 1).

\section{The Vaccine Factor}

A key plank to proving the Zika-microcephaly link would be, according to World Health Organization officials to follow women during their pregnancy to document what they are exposed to and their future health outcomes. But very few eyes have been turned towards the fact that in Brazil, the BCG vaccine (watered down cow tuberculosis) is given to all children during the neonatal period. Dissemination of Mycobacterium bovis (Mb) after 


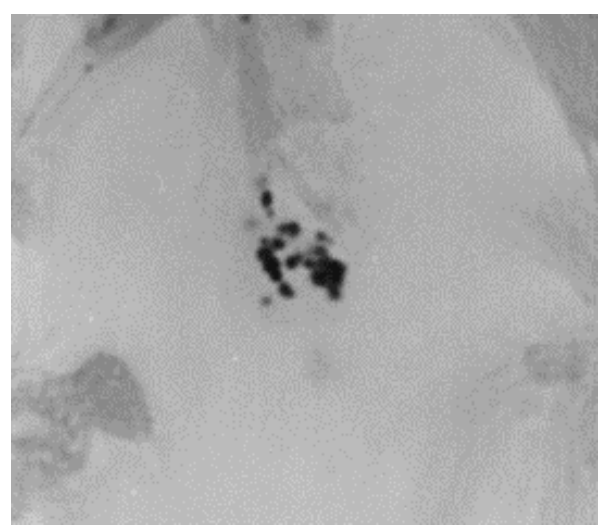

Figure 1. Small darkly-stained circular-shaped viral-like Cell-Wall-Deficient mycobacterial forms (Source: CDC).

BCG vaccination, with a fatal outcome, may occur in up to 30\% of infants with severe combined immunodeficiency [13].

Yet according to The Royal Children's Hospital in Melbourne, among those who should definitely not get the BCG vaccine are pregnant women and those immunosuppressed or that already have TB or AIDS. How does one know this? In Brazil, they often do not [14].

In the UK, the NHS [15] reports that most reactions to BCG reported through their Yellow Card Scheme have been minor, such as redness and swelling at the injection site, rashes, fever and vomiting, some of the very symptoms attributed to the Zika virus.

\section{A Forgotten Cause of Microcephaly}

Zika (Figure 2) circulated for decades in Africa without raising fears of microcephaly and so far there is no scientific description of a mechanism in literature by which Zika might cause the disorder or effect the development of the nervous system. Microcephaly is due to the failure of normal brain growth and is defined by many as a head circumference that is more than three standard deviations below the mean for age and gender. The causes of microcephaly are varied, but congenital infection is generally considered one of the most common [15]. A lot of babies with microcephaly end up being pretty limited in their capacity. They have trouble eating, they can't talk, they have trouble sitting up, and they can't walk, with obvious signs of defects in the development of the neuromotor system. It can indeed be pretty devastating. Usually microcephaly via prenatal infection tends to have poorer outcomes for the newborn.

Although today the cause of microcephaly in most babies is unknown, early medical references of microcephaly just prior to the $20^{\text {th }}$ century, such as that written up by Alexis Thomson MD [16], Assistant Surgeon for the Royal Infirmary, Edinburgh, leave little doubt that most victims born with microcephaly not only died early from tuberculosis but had intermittent seizures and paralysis, not unlike the Guillain-Barré syndrome.

Furthermore, the 1952 pilot study that put the Zika Virus on the map failed to give testimony to any congenital or microcephalic findings in mice. Five years later, in 1957, Gluecksohn-Waelsch [17] certainly reported that experimentally, when brain emulsions with tuberculosis (Complete Freund's adjuvant or CFA) were injected into female mice beginning prior to conception-abnormalities were observed in the nervous system of $8 \%$ to $9 \%$ of the embryos born to these mice-including microcephaly. Microcephaly is primarily due to suppression of normal neural differentiation, a thinning of the walls of the neural tube, and an abnormal neural fold closure. The dose of the brain homogenate Gluecksohn-Waelsch used for immunization in his CFA was not adequate, however, to elicit autoimmune encephalitis by itself.

Among the causes for infections to the nervous system the most common types are pyogenic, tuberculosis and aseptic (viral) any of which can cause microcephaly. But currently, more than 2 billion people (i.e., one third of the world's population) are infected with tuberculosis (TB), of which approximately $10 \%$ will develop clinical disease. The incidence of central nervous system (CNS) TB is related to the prevalence of TB in the community, which is still the most common type of chronic CNS infection in developing countries like Brazil. Central Nervous System HIV infection also can cause microcephaly_but Tuberculosis (TB) remains uniquely impor- 
tant among the acquired immune deficiency syndrome (AIDS/HIV)-associated opportunistic infections: and at the same time TB presents the greatest public health hazard worldwide [18]. Mycobacterial diseases rank among the most frequent and important complications of AIDS. As well as its principal cause of death. Whether such developmental, cognitive delay, microcephaly and corticospinal tract signs are as a result to HIV or the mycobacteria remains an open question. Most CNS HIV infection in children is accompanied by Mycobacteria avium or TB.

\section{A Less Well-Known Side of Guillain-Barré Syndrome (GBS)}

Is there a link between Zika fever in infected adults and neurological conditions such as the Guillain-Barre syndrome? Zika's link with Guillain-Barréis, as with microcephaly, still just an association, and not a definitive cause-and effect relationship. Although the occurrence of Guillain-Barre Syndrome and Guillain-Barré-like radiculomyelopathy in central nervous system tuberculosis is not well recognized, it certainly has been well-reported-starting with Wadia in 1973 [19]. Not only has the association of GBS and TB been repeatedly reported [20]-[29], but in addition the tuberculosis bacilli has actually been demonstrated in the nerve roots at necropsy in patients with the salient features of the Guillain-Barre syndrome [30]. This led de la Torre, Morís, Martinez and Montez to conclude the need to consider TB in all patients with GBS [31].

\section{French Sixth Army Western Front European Theatre during WW1-1916}

To the end, Guillain suspected an unknown infection behind the paralyzing Syndrome bearing his name. And it wasn't influenza. Guillain and Barré met while medical students at the Saltpêtrière in turn-of-the century Paris. Later, as neurologists, they served in the French Sixth Army during WWI. Along with neurologist Andre Strohl, they soon attended to two soldiers who had become partially paralyzed. One of these victims had fallen over when he had put his backpack on and had been unable to get up. Both soldiers quickly recovered.

Guilllain and Barré's 1916 paper noted that their paralysis was ascending in that it traveled from the lower extremities upwards. Also its victim's reflexes where reduced, and, moreover, there was a substantially increased protein count in the spinal (cerebrospinal) fluid when a spinal tap was performed. Guillain realized that the quantity of the increased protein in the soldier's cerebrospinal fluid was a crucial discovery. Only two common infections of the time, syphilis and tuberculosis, would have shown such a sizeable protein increase. But with syphilis, such an increase in spinal fluid protein was a hit-or-miss affair. Graman found only 9 out of 47 syphilitic patients (19\%) with elevated protein in their CSF (Cerebrospinal Fluid) [32]. And viruses, such as "influenza” didn't come anywhere near the elevation in protein shown in the spinal fluid of TB patients [33].

Also, although the cause of Guillain-Barré Syndrome in infection is still by no means clear, for some time it has been a majority view that GBS represents a cell-mediated, delayed, hypersensitivity reaction—just the sort of reaction that characterizes both tuberculosis and its tuberculin skin test [34].

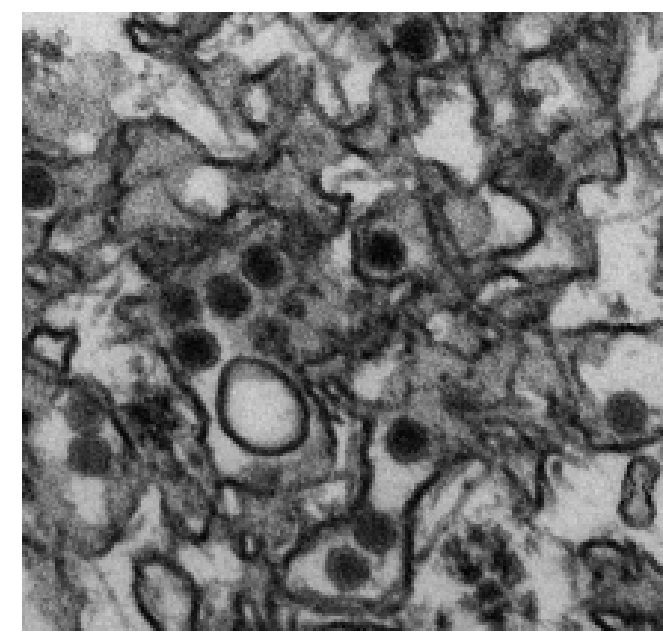

Figure 2. Electron microscope images of the Zika Virus with a size of around $50 \mathrm{~nm}$ (Source, CDC). 
Peiris, in the British Medical Journal, demonstrated the direct invasion of nerve roots by tubercle bacilli in Guillain-Barré syndrome [30]. Lumsden reviewed how experimentally one animal could be injected with another's brain tissue combined with paraffin oil and heat-killed tuberculosis to experimentally inflame the brain (encephalitis).

Waksman and Adams, using rabbits, did the same, creating a marked increase of protein in their spinal fluid, which exactly mimicked the Guillain-Barré Syndrome [35]. It has long been known that Experimental Allergic Encephalopathy (EAE), a disease created experimentally with tubercular proteins can, in certain cases mimic Guillain-Barre syndrome. It has been produced in experimental animals by immunization of peripheral nerve tissues with Freund's adjuvant, a mixture of supposedly dead tuberculous bacilli in oil.

Guillain died in 1961 and Barré in 1967. Having first published the relationship between ascending paralysis and an increased protein count in cerebrospinal fluid in 1916, they had seen a huge increase in knowledge with regard to their syndrome, as well as witnessed the use of early intensive care techniques to cope with it. To the end, Guillain suspected an unknown infection as the cause of GBS and dismissed suggestions, made ten years earlier by Bannwarth, that the cause was due to allergy or that it was due to some vague "auto-immune" disease.

\section{Mosquito Killing Dilemma}

At one point, Anthony Fauci, director of the National Institute of Allergy and Infectious Diseases, said there will not be a vaccine ready to combat Zika for at least several years. So, in the absence of further answers, WHO is stressing that mosquito control in affected areas-helping eradicate mosquitoes and taking precautions to avoid their bite-is the safest course for people living in those regions.

But is eradicating mosquitoes really the safest course for Brazil? The use of pesticides in Brazil grew by more than 162 percent from 2000 to 2012, according to the latest report by the Brazilian Association of Collective Health (ABRASCO), making the country the number one consumer of pesticides in the world. According to this entity, the Brazilian agriculture sector purchased more than 823,000 tons of pesticides in 2012 alone [36].

A. Paulo Peterson, director of the Brazilian Agro-Ecology Association warned: "Not only are we using more [pesticides] but we are using more powerful, stronger pesticides. We have been forced to import pesticides which were not even allowed in Brazil to combat pests which attacked GM soybean and cotton plants.” Previous studies have linked pesticide exposure to microcephaly and other birth defects [37]. In the case of the insecticide atrazine, one study concluded: "The presence versus absence of quantifiable levels of atrazine or a specific atrazine metabolite was associated with fetal growth restriction... and small head circumference for sex and gestational age..." [38].

So for now, experts say, the best modes of prevention are to intensify use of the older methods of mosquito control. One old method that should be, but that is not getting serious attention, would be the use of DDT-a powerful pesticide that is banned in many countries because of the ecological damage documented in the 1962 book "Silent Spring". Still it is being mentioned and some experts defend its use for Zika control.

“That concern about DDT has to be reconsidered in the public health context”, said Dr. Lyle R. Petersen, director of the division of vector-borne diseases at the Centers for Disease Control and Prevention. He said that "the use damage to fish and wildlife stemmed from widespread outdoor use of DDT in agriculture, not the use of small amounts on the walls inside homes to kill mosquitoes” [39]. In the meanwhile, it was the extensive use of DDT by American forces in post-WW2 Guam, that wiped the AedesEgypti off of that island altogether.

\subsection{Sexual Transmission?}

The first case of Zika virus contracted in US mainland, confirmed in Texas, was only the second documented example of the mosquito-delivered virus being passed through sexual contact [40]. This notion began, when in December 2013, during a “Zika virus" outbreak in French Polynesia, a patient in Tahiti sought treatment for a serous bloody discharge in his semen (hematospermia), and Zika was identified from this. This observation was said to support the possibility that Zika could be transmitted sexually [41].

By 1972, five years before gays started dying in the United States, Rolland wrote Genital Tuberculosis, a Forgotten Disease? [42] And ironically, in 1979, on the eve of AIDS recognition, Gondzik and Jasiewicz showed that even in the laboratory, genitally infected tubercular male guinea pigs could infect healthy females through their semen by an HIV compatible ratio of one in six, or 17\%, prompting him to also warn his patients that not only was tuberculosis a sexually transmitted disease, but also the necessity of the application of suitable 
contraceptives such as condoms to avoid it [43]. Gondzik’s solution and pre-AIDS date of publication are chilling; his findings too significant to ignore. Even in syphilis at its most infectious stage, successful transmission in humans was possible only in $30 \%$ of contacts [44].

By 1954, a pattern had emerged at Dr. John Lattimer's Center for Genitourinary Tuberculosis. Men who developed tuberculosis epididymitis (inflammation of the testicles) were usually found to have an active focus of tubercular infection in their prostate, and cultures of their semen were frequently positive for tubercle bacilli [45].

\subsection{Zika as a Cause of Brain Calcifications?}

In a recent 2016 review of Zika dealing with possible brain abnormalities appearing with Zika in the journal Ultrasound ObstetGynecol, Melo et al. mention of their first case: "Anomalies [with Zika] were limited to the brain and included brain atrophy with coarse calcifications involving the white matter of the frontal lobes, including the caudate, lentostriatal vessels and cerebellum... Corpus callosal and vermian dysgenesis and enlarged cisterna magna were observed.” [46] (Figure 3).

Melo's second Zika case showed similar brain lesions, with brain calcification, albeit less. The only problem was that among the Flaviviruses, which Zika is, such brain insults and pathologic findings are practically unheard of with the exception of isolated reports linking West Nile Encephalitis to a few cases. Melo et al. concluded that "until more cases are diagnosed and histopathological proof obtained, the possibility of other causes besides Zika cannot be ruled out" [46].

But curiously, the calcification and lesions purported to be from the Zika find their precise counterparts in CNS tuberculosis (Figure 4). Intracranial calcification are common with tubercular involvement, particularly in the white matter of the frontal lobes, the cerebellum and at the brains base-and develop in $20 \%$ to $48 \%$ of patients with cerebral tuberculous [47]. In a series of 25 consecutive children who recovered from Central Nervous System TB, seventeen developed radiologically demonstrable intracranial calcifications [48].

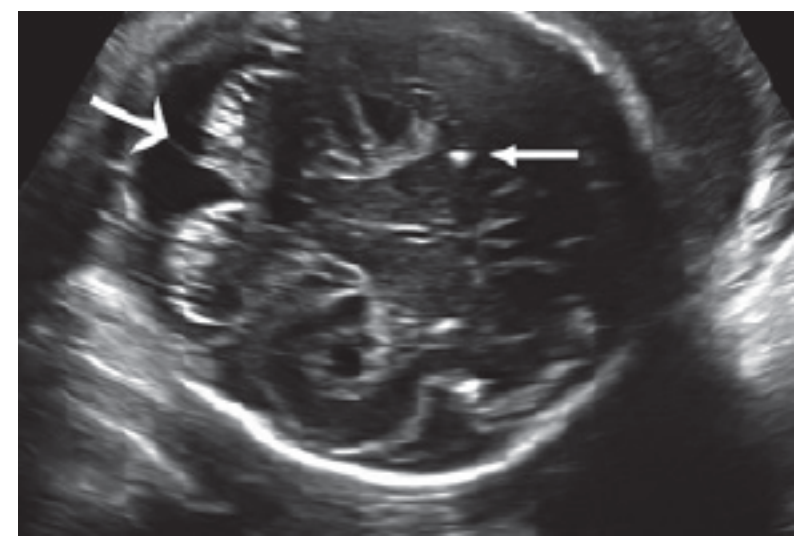

Figure 3. Trans-abdominal axial ultrasound image shows cerebral calcifications in a Zika patient (Source: CDC).

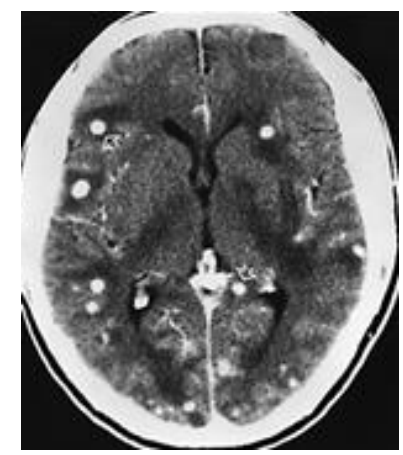

Figure 4. Multiple calcifications in the brain in cerebral Tuberculosis (Source: CDC). 


\section{Discussion/Conclusion}

On February 10, 2016, the New England Journal of Medicine [49] published a study done in Slovania based on a single case, entitled Zika Virus Associated with Microcephaly. Obviously "associated with" did not mean that the Zika was causative for microcephaly. The authors admitted that "Our discussion includes details of fetal imaging and pathological and virologic analyses". And that was about the only "analyses" they did. An accompanying Editorial in the same issue [50] weighed in that "The findings of this case report do not provide absolute proof that Zika virus causes microcephaly" although... "the evidence in this case report makes the link stronger". But, making "the link stronger" is still far from providing "absolute proof" that the Zika caused microcephaly.

The NEJM paper used RT-PCR with "Zika-specific primers” as well as deep sequencing (IonTorrent), which itself includes a RT-PCR step. Also, because deep sequencing works by assembling fragments, we don't actually know that there was a complete Zika genome anywhere in the tissue-just that there was a representative collection of fragments covering the complete genome. Furthermore the EM (Electron Microscope) pictograph suggests the particles of a viral infection, but doesn't independently identify the virus. So we have three different techniques whose flaws don't quite cover for each other.

One virologist even admitted: “I don't think we know enough to say that presence of a virus in the fetus is automatically a bad thing. We do have a virome and the fetus acquires it from the amniotic fluid. It's mostly phages but there are likely to be animal viruses there as well." But where do "phages" come from? They do not come from viruses, but from virulent bacteria and mycobacteria.

In this paper we have already reviewed other flaws related to the present methodology to detect the Zika "virus". We have also presented the views of experts in the field that until more cases are diagnosed and further histologic proof and scientific evidence are established, the possibility of "other causes" cannot be ruled out. At the same time we have established what a prime candidate for such another cause might look like-the Mycobacterium tuberculosis complex-an infectious agent with transmissible, filterable, viral-like forms; an infectious agent that can be transmitted by the very same Aedes mosquitoes which carry Zika; a known neurotrophic agent that already has infected at least one-third of the people in the world and is extremely prevalent in Brazil; that can cause microcephaly, disrupt brain growth, instigate fever of unknown origin, be sexually transmissible, create joint pains and rashes, cross the placenta in its preferred, tiny, cell-wall-deficient forms, instigate the Guillain-Barré syndrome, and create cranial calcifications. And all of these are not by supposition or conjecture-but by peer-reviewed fact. The only reason why the BCG vaccine (watered down cow tuberculosis) is given to all Brazilian children during the neonatal period is to protect the soon to be infant and then toddler against miliary, blood born, and the cerebral forms of tuberculosis. Yet such administration of the BCG vaccine is forbidden by the Royal Children's Hospital in Melbourne to pregnant women in general, no less neonates that have contracted TB, even latent TB-which often goes undetected. Yet the Aedes aegypti and other Aedes species of mosquito have the potential to spread just that. Such a potential is one that science can no longer afford to either ignore or not to investigate.

\section{References}

[1] Maron, D.F. (2016) What Would It Take to Prove the Zika-Microcephaly Link-Public Health Officials Are Not Yet Ready to Say the Connection Is Causal. Scientific American. www.scientificamerican.com/article/what-would-it-take-to-prove-the-zika-microcephaly-link1/

[2] CDC, Centers for Disease Control and Prevention (2016) Questions and Answers for Obstetrical Healthcare Providers: Pregnant Women and Zika Virus Infection. http://www.cdc.gov/zika/hc-providers/qa-pregnant-women.html

[3] Palese, P. (2004) Influenza: Old and New Threats. Nature Medicine, 10, S82-S87. http://dx.doi.org/10.1038/nm1141

[4] Dick, G.W.A., Kitchen, S.F. and Haddow, A.J. (1952) Communications: Zika Virus-Isolations and Serological Specificity. Transactions of the Royal Society of Tropical Medicine and Hygiene, 46, 509-520. http://dx.doi.org/10.1016/0035-9203(52)90042-4

[5] Pinto de Oliveira, G., Wieczorek Torrens, A., Bartholomay, P. and Barreira, D. (2013) Tuberculosis in Brazil: Last Ten Years Analysis-2001-2010. The Brazilian Journal of Infectious Diseases, 17, 218-233. http://dx.doi.org/10.1016/j.bjid.2013.01.005

[6] World TB Day in Brazil Calls for a New TB Campaign. http://www.stoptb.org/assets/documents/countries/partnerships/World\%20TB\%20Day\%20in\%20Brazil\%20calls\%20fo r\%20a\%20new\%20TB\%20campaign.pdf 
[7] Lavender, C.J., Fyfe, J.A.M., Azuolas, J., Brown, K., Evans, R.N., Ray, L.R. and Johnson, P.D.R. (2011) Risk of Buruli Ulcer and Detection of Mycobacterium ulcerans in Mosquitoes in Southeastern Australia. PLOS/Neglected Tropical Diseases, 5, e1305. http://dx.doi.org/10.1371/journal.pntd.0001305

[8] Banerjee, R., Banerjee, B.D., Chaudhury, S. and Hati, A.K. (1991) Transmission of Viable Mycobacterium leprae by Aedesaegypti from Lepromatous Leprosy Patients to the Skin of Mice through Intermittent Feeding. Tropical and Geographical Medicine, 42, 97-99.

[9] Narayanan, E., Manja, K.S., Kirchheimer, W.F. and Balasubrahmanyan, M. (1972) Occurrence of Mycobacterium leprae in Arthropods. Leprosy Review, 43, 194-198. http://dx.doi.org/10.5935/0305-7518.19720026

[10] Narayanan, E., Sreevatsa, Kirchheimer, W.F. and Bedi, B.M. (1977) Transfer of Leprosy Bacilli from Patients to Mouse Footpads by Aedesegypti. Leprosy Review, 49, 181-186.

[11] Narayanan, E., Sreevatsa, Raj, A.D., Kirchheimer, W.F. and Bedi, B.M. (1978) Persistence and Distribution of Mycobacterium leprae in Aedesegypti and Culexfatigans Experimentally Fed on Leprosy Patients. Leprosy in India, 50, 2637.

[12] Golyshevskaya, V.I. (1991) The Role of Coccoid Ultrafine Forms of Mycobacteria in the Transmission of the Mycobacterial Infection. Pneumoftiziologia, 40, 11-13.

[13] Roxo-Junior, P., Silva, J., Andrea, M., Oliveira, L., Ramalho, F., Bezerra, T. and Nunes, A.A. (2013) A Family History of Serious Complications Due to BCG Vaccination Is a Tool for the Early Diagnosis of Severe Primary Immunodeficiency. Italian Journal of Pediatrics, 39, 54. http://www.ijponline.net/content/39/1/54 http://dx.doi.org/10.1186/1824-7288-39-54

[14] The Royal Children's Hospital Melbourne. BCG Vaccine for TB Tuberculosis. http://www.rch.org.au/kidsinfo/fact_sheets/BCG_vaccine_for_TB_Tuberculosis/

[15] NHS. Who Should Have the BCG (TB) Vaccine? National Health Service. http://www.nhs.uk/conditions/vaccinations/pages/bcg-tb-vaccine-side-effects.aspx

[16] Thomson, A. (1894) Microcephaly and Infantile Hemiplegia in the Journal of Anatomy and Physiology, Normal and Pathological, Human and Comparative. Humphray, G.M., Turner, W. and McKendrick, J.G., Eds., Vol. 28, Charles Griffin and Company, London, 419-444.

[17] Gluecksohn-Waelsch, S. (1957) The Effect of Maternal Immunization against Organ Tissues on Embryonic Differentiation in the Mouse. Journal of Embryology and Experimental Morphology, 5, 83-89.

[18] Hill, A.R. (1991) Mycobacterial Infections in AIDS. Canadian Journal of Infectious Diseases, 2, 19-29. http://dx.doi.org/10.1155/1991/476503

[19] Wadia, N.H. (1973) Radiculomyelopathy Associated with Spinal Meningitides (Arachnoiditis) with Special Reference to the Spinal Tuberculous Variety. In: Spillane, J.D., Ed., Tropical Neurology, Oxford University Press, London, 6372.

[20] Canham, E.M. and Iseman, M.D. (2014) Guillain-Barre Syndrome Related to Pulmonary Tuberculosis. Annals of the American Thoracic Society, 11, 855-857. http://dx.doi.org/10.1513/AnnalsATS.201403-101LE

[21] Vyravanathan, S. and Senanayake, N. (1983) Guillain-Barré Syndrome Associated with Tuberculosis. Postgraduate Medical Journal, 59, 516-517. http://dx.doi.org/10.1136/pgmj.59.694.516

[22] Chong, V.H., Joseph, T.P., Telisinghe, P.U. and Jalihal, A. (2007) Chronic Inflammatory Demyelininatingpolineuropathy Associated with Intestinal Tuberculosis. Journal of Microbiology, Immunology and Infection, 40, 377-380.

[23] Soehard, Y.Z., Yuhanissa, A., Thein, S.S., Rohana, A.G., Fauzi, A.R. and Norlinah, M.I. (2005) AMSAN Variant of Guillain-Barré Syndrome Progressing to Chronic Inflammatory Demyelinating Polyneuropathy in a Patient with Marfan's Syndrome and Pulmonary Tuberculosis. Medical Journal of Malaysia, 60, 655-656.

[24] Fernández-Fúnez, A., Gómez Garrido, J., Alamillo, A. and Sáez, L. (2007) Demyelinating Polyneuropathy as the Honest Form of Lymph Node Tuberculosis. Paradox Response in an Immunocompetent Patient. Medicina Clínica, 129, 78-79. http://dx.doi.org/10.1157/13106942

[25] Sabriá Mestres, J., Alijotas Reig, J., Ordi Ros, J., Biosca Gómez de Tejada, M. and Sumalla Suñé, J. (1985) Guillain-Barré Syndrome and Tuberculosis. A Chance Association? Revista Clínica Española, 176, 320-321.

[26] Soysal, A., Aysal, F., Calıskan, B., DoganAk, P., Mutluay, B., Sakallı, N., Baybas, S. and Arpac1, B. (2011) Clinico-Electrophysiological Findings and Prognosis of Guillain-Barre Syndrome-10 Years' Experience. Acta Neurologica Scandinavica, 123, 181-186. http://dx.doi.org/10.1111/j.1600-0404.2010.01366.x

[27] Taha, A.A.M. and Tee, K.H.A. (2012) Guillain-Barré Syndrome Associated with Pulmonary Tuberculosis. BMJ Case Reports.

[28] Rekha, M.C. and Prakash, G.M. (2014) Guillain Barre Syndrome Due to Pulmonary Tuberculosis. Indian Journal of 
Fundamental and Applied Life Sciences, 4, 408-410. http://www.cibtech.org/jls.htm

[29] Ramarao, T., Bhaskar, Y. and Vijaya Bhaskar, M. (1983) Guillain-Barre Syndrome in Pulmonary Tuberculosis. Indian Journal of Tuberculosis, 30, 118-120.

[30] Peiris, J.B., Wickremasinghe, H.R. and Chandrasekara, M.A. (1974) Letter: Tuberculous Polyradiculitis. BMJ, 4, 107. www.ncbi.nlm.nih.gov/pmc/articles/PMC1612152/

[31] De la Torre, R.G., Morís, G., Martínez, D.P. and Montes, I.C. (2010) Guillain-Barré Syndrome, Tuberculosis and Inflammatory Bowel Disease: A Multiple Association. International Archives of Medicine, 3, 15. http://dx.doi.org/10.1186/1755-7682-3-15

[32] Graman, P.S., Trupei, M.A. and Reichman, R.C. (1987) Evaluation of Cerebrospinal Fluid in Asymptomatic Late Syphilis. Sexually Transmitted Diseases, 14, 205-208. http://dx.doi.org/10.1097/00007435-198710000-00005

[33] Corston, R.N., McGale, E.H.F. and Stonier, C. (1981) Cerebrospinal Fluid Amino Acid Concentrations in Patients with Viral and Tuberculous Meningitis. Journal of Neurology, Neurosurgery, and Psychiatry, 44, 791-795. http://dx.doi.org/10.1136/jnnp.44.9.791

[34] Thomas, P.K. (1978) Screening for Peripheral Neuropathy in Patients Treated by Chronic Haemodialysis. In: Scott, S.R.B., Ed., Price's Textbook of the Practice of Medicine, The English Language Book Society and Oxford University Press, London, 1312.

[35] Waksman, B.H. and Adams, R.D. (1955) Allergic Neuritis: An Experimental Disease of Rabbits Induced by the Injection of Peripheral Nervous Tissue and Adjuvants. The Journal of Experimental Medicine, 102, 213-236. http://dx.doi.org/10.1084/jem.102.2.213

[36] Alves, L. (2015) Brazil Shown to Be Largest Global Consumer of Pesticides. The Rio Times, 5 May 2015.

[37] Lu, J.L. (2009) Comparison of Pesticide Exposure and Physical Examination, Neurological Assessment, and Laboratory Findings between Full-Time and Part-Time Vegetable Farmers in the Philippines. Environmental Health and Preventive Medicine, 14, 345-352. http://dx.doi.org/10.1007/s12199-009-0105-X

[38] Chevrier, C., Limon, G., Monfort, C., Rouget, F., Garlantézec, R., Petit, C., Durand, G. and Cordier, S. (2011) Urinary Biomarkers of Prenatal Atrazine Exposure and Adverse Birth Outcomes in the PELAGIE Birth Cohorts. Environmental Health Perspectives, 119, 1034-1041. http://dx.doi.org/10.1289/ehp.1002775

[39] Pollack, A. (2016) New Weapon to Fight Zika: The Mosquito. The New York Times—Health Section.

[40] Glenza, J. (2016) Zika Virus: First Case Contracted in US Was Sexually Transmitted, Say Officials. The Guardian.

[41] Musso, D., Roche, C., Robin, E., Nhan, T., Teissier, A. and Cao-Lormeau, V.-M. (2015) Potential Sexual Transmission of Zika Virus. Emerging Infectious Diseases, 21, 359-361. http://dx.doi.org/10.3201/eid2102.141363

[42] Rolland, R. and Schellekens, L. (1972) Genital Tuberculosis, a Forgotten Disease. Nederlands Tijdschrift voor Geneeskunde, 116, 2377-2378.

[43] Gondzik, M. and Jasiewicz, J. (1979) Experimental Study on the Possibility of Tuberculosis Transmission by Coitus. Zeitschrift fur Urologie und Nephrologie, 72, 911-914.

[44] Smith, L.H. and Wyngaarden, J.B. (1988) Cecil Textbook of Medicine. WB Saunders, Philadelphia.

[45] Lattimer, J.K. and Colmore, H.P. (1954) Transmission of Genital Tuberculosis from Husband to Wife via the Semen. American Review of Tuberculosis, 69, 618-624.

[46] Melo, A.S.O., Malinger, G., Ximenes, R., Szejnfeld, P.O., Sampaio, S.A. and Bispo de Filippis, A.M. (2016) Zika Virus Intrauterine Infection Causes Fetal Brain Abnormality and Microcephaly: Tip of the Iceberg? Ultrasound in Obstetrics \& Gynecology, 47, 6-7.

[47] Garg, R.K. (1999) Tuberculosis of the Central Nervous System. Postgraduate Medical Journal, 75, 133-140. http://dx.doi.org/10.1136/pgmj.75.881.133

[48] Lorber, J. (1952) The Incidence and Nature of Intracranial Calcifications after Tuberculous Meningitis. Archives of Disease in Childhood, 27, 542-551. http://dx.doi.org/10.1136/adc.27.136.542

[49] Mlakar, J., Korva, M., Tul, N., et al. (2016) Brief Report: Zika Virus Associated with Microcephaly. New England Journal of Medicine, 374, 951-958. http://www.nejm.org/doi/pdf/10.1056/NEJMoa1600651

[50] Rubin, E.J., Greene, M.F. and Baden, L.R. (2016) Editorial: Zika Virus and Microcephaly. New England Journal of Medicine, 374, 984-985. http://www.nejm.org/doi/full/10.1056/NEJMe1601862 